\title{
Fractions of Concern: Challenges and Strategies for the Safety Assessment of Biological Matter in Cosmetics
}

\author{
Fabian P. Steinmetz ${ }^{1}$, James C. Wakefield ${ }^{2}$ and Ray M. Boughton ${ }^{3, *}$ \\ 1 Delphic HSE (Europe) B.V., 1118CN Schiphol, The Netherlands; fabian.steinmetz@delphichse.com \\ 2 Delphic HSE Solutions (HK) Ltd., Shatin, Hong Kong, China; james.wakefield@delphichse.com \\ 3 Delphic HSE Solutions Ltd., Camberley GU15 3YL, UK \\ * Correspondence: ray.boughton@delphichse.com
}

Citation: Steinmetz, F.P.; Wakefield,

J.C.; Boughton, R.M. Fractions of

Concern: Challenges and Strategies for the Safety Assessment of

Biological Matter in Cosmetics.

Cosmetics 2021, 8, 34. https://

doi.org/10.3390/cosmetics8020034

Academic Editor: Kalliopi Dodou

Received: 15 April 2021

Accepted: 30 April 2021

Published: 4 May 2021

Publisher's Note: MDPI stays neutral with regard to jurisdictional claims in published maps and institutional affiliations.

Copyright: (c) 2021 by the authors. Licensee MDPI, Basel, Switzerland. This article is an open access article distributed under the terms and conditions of the Creative Commons Attribution (CC BY) license (https:// creativecommons.org/licenses/by/ $4.0 /)$.

\begin{abstract}
Cosmetic ingredients based on more or less refined biological matter (plants, fungi, bacteria, etc.) are gaining popularity. Advances in green chemistry and biotechnology are supporting this general trend further. Following numerous bans on the use of newly generated animal testing data in cosmetic safety assessments, and the worldwide demand for "cruelty-free" products, many alternative methods have been developed to assess the toxicity of ingredients. Whilst great strides have been, and continue to be, made, the area of systemic toxicity is one where international harmonisation and regulatory acceptance is still evolving. A strategy for the fractional assessment of biological matter is suggested to make approaches, such as threshold of toxicological concern (TTC) methodology, fit for purpose. Within this strategy, analytical data are used to generate compound classes which are quantified and assessed separately. Whilst this strategy opens new windows for assessing the safety of complex mixtures with a lack of toxicological data, it also raises awareness of the increasing complexity of cosmetic formulations and the general problem of additivity/synergy being rarely addressed. Extremely complex mixtures are and will be a growing challenge for safety assessors.
\end{abstract}

Keywords: safety; cosmetics; botanicals; toxicology; TTC

\section{Introduction}

Cosmetic products may contain a plethora of chemical compounds which themselves may originate from different sources. These sources refer to biological matter from plants, fungi, animals, bacteria and algae but also mineral matter, such as fractions from mineral oil or pigments, and of course derivatives and combinations due to chemical reactions and biotechnological processes. As a rule of thumb, the less purification of educts and products is conducted, the more complex the chemistry of the resulting ingredient. However, public perspective, international trade and advances in green chemistry and biotechnology are creating a shift towards more biological matter from plants, fungi, algae and bacteria as ingredients for consumer goods, such as cosmetics [1-3]. Although biological ingredients may be perceived as natural and safer by consumers, complex chemical mixtures are difficult to assess, independent from their origin. In general, most plant extracts are complex mixtures and prone to a certain variability based on season, utilised plant parts and solvents but also process parameters, such as temperature and pressure. It is easy to imagine how difficult safety assessments might become when products are assessed containing multiple botanicals and related materials. Furthermore, such challenges did not become easier by voluntary and mandatory animal testing bans, because these are limiting toxicological testing batteries.

There is a worldwide shift to "cruelty-free" cosmetic products, for example manifested in Regulation (EC) No. 1223/2009 [4] that banned animal testing in the EU for cosmetic products and ingredients. Nevertheless, the safety of the ingredients used in a cosmetic product is a key feature for the safety of cosmetics as described in SCCS/1602/18 [5]. 
Historical data from animal testing have been used by safety assessors to exclude the risks of significant skin and eye irritation, skin sensitisation, genotoxicity and systemic toxicity. In light of the animal testing bans for cosmetics, most notably in the EU, and the general drive to move away from risk assessments based on animal test data, alternative approaches are required. Whilst there are nowadays many alternative testing methods available, e.g., bacterial mutation test (Ames test), Hen's egg test on chorioallantoic membrane (HET-CAM) assay, bovine corneal opacity and permeability (BCOP) assay, direct peptide reactivity assay (DPRA), and human cell line activation test (h-CLAT), systemic toxicity can only be partially addressed, for example, when modes of action (MoA) are known [6]. Hence, current strategies include MoA-driven testing/analysis, investigations on the history of safe use [7], read-across approaches [8] and the threshold of toxicological concern (TTC) methodology $[9,10]$. It should be mentioned that in a weight-of-evidence (WoE) approach, combinations of those strategies are possible, for example, an on-its-own insufficient readacross could be supported by negative in silico predictions/bioassay results for a potential MoA and/or by limited history of safe use data.

Particularly, the TTC is a popular way to justify safety of biological matter, such as plant extracts or ferments, with regard to systemic toxicity. This manuscript asks critically whether the current TTC approach or derivatives thereof are fit for purpose but also suggests further refinements which allow for more flexibility based on the available data.

\section{Threshold Approaches}

The current TTC approach is based on "Cramer classes" [11], which itself is a classification system for chemical compounds. The origin of this approach lies in the assessment of low-level substances in the human diet. Basically, there are three different classes which are categorised with increasing toxicological concern. Class I is more associated with endogenous or rather inert compounds, while Class III is more associated with drug-like or reactive (potentially toxic) compounds. Class II fits the spectrum in between those two classes. Many chemoinformatic tools, such as ToxTree v3.1.0 (Ideaconsult Ltd, Brussels, Belgium) [12] or OECD QSAR Toolbox 4.4.1. (OASIS LMC, Burgas, Bulgaria) [13], use this decision tree or derivatives thereof.

Munro and colleagues assigned threshold values for those classes based on 95th percentiles of no-observed-adverse-effect-level (NOAEL) data, Yang and colleagues validated and refined these thresholds with new data in 2017 [9,10]. The resulting thresholds are $46 \mu \mathrm{g} / \mathrm{kg} \mathrm{bw} /$ day for Cramer Class I and $2.3 \mu \mathrm{g} / \mathrm{kg}$ bw /day for Cramer Class II and III (with a bodyweight defined as $60 \mathrm{~kg}$ ). If a structural alert for genotoxicity is triggered, then the threshold should be reduced to $0.0025 \mu \mathrm{g} / \mathrm{kg}$ bw/day according to Kroes and colleagues [14] - this can be considered as an unofficial "fourth Cramer class". Nevertheless, in vitro genotoxicity testing is considered preferable, which limits the necessity for in silico genotoxicity investigations. In Figure 1, as an example, three unrelated but chemically similar compounds were investigated with ToxTree v3.1.0 [12], followed up by the assigning of appropriate classes and thresholds.

Although not the focus of this manuscript, the dermal sensitisation threshold (DST) shall not remain unnamed. Here, a similar approach is applied utilising reactivity domains (cf. structural alerts) and skin sensitisation data [15-18].

It must be emphasised that the TTC approach is intended for individual compounds and not for mixtures, and that assigning $2.3 \mu \mathrm{g} / \mathrm{kg}$ for all biological matter (after genotoxicity was excluded via in vitro testing) might be considered overly conservative, i.e., safe products with low to moderate exposure might fail a safety assessment. With regard to TTC for biological matter, Kawamoto and colleagues [19] suggested to either use a Cramer Class III threshold for botanicals (which was found protective) or to use the 1st percentile of their data analysis: $663 \mu \mathrm{g} /$ day or $11.05 \mu \mathrm{g} / \mathrm{kg}$ bw/day (bodyweight defined as $60 \mathrm{~kg}$ ). Both approaches are rather conservative and try to comprise the huge variety in toxicity. Biological raw materials are complex mixtures with a large chemical variability 
and therefore a one-size-fits-all approach might become overly conservative for many raw materials of interest.

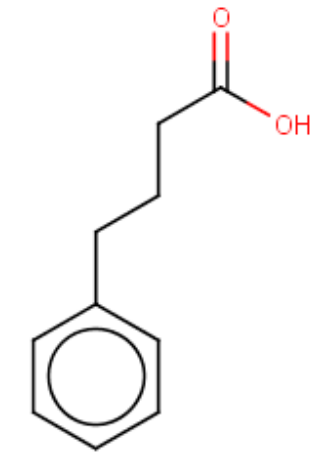

Cramer Class I $46 \mu \mathrm{g} / \mathrm{kg}$ bw/day

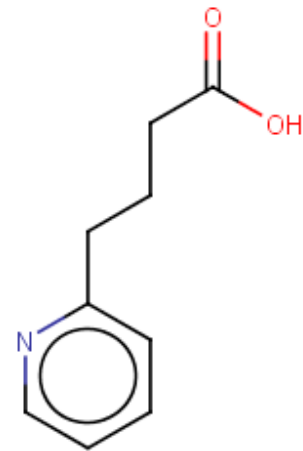

Cramer Class II $2.3 \mu \mathrm{g} / \mathrm{kg}$ bw/day<smiles>O=C/C=C/Cc1ccccc1</smiles>

Genotox Alert $0.0025 \mu \mathrm{g} / \mathrm{kg}$ bw/day

Figure 1. Three structurally similar compounds investigated via ToxTree v3.1.0. From left to right: 4-phenylbutyric acid (CAS 1821-12-1), 4-(2-pyridinyl) butanoic acid (CAS 102879-51-6) and 4-phenylcrotonaldehyde (CAS 13910-23-1).

\section{Fractions of Concern}

As biological matter may contain a huge variety of chemical compounds, it is best to either conduct a literature search for relevant analytical data or to perform a chemical analysis for the material of interest. Specifications and certificates of analysis may help with standardisation, so chemical data are transferable between batches and raw material suppliers. In case this is not possible, information on taxonomy, plant parts, solvents/processes used, etc., may help with approaches to overcome data gaps/uncertainties. In general, conservative estimations/safety buffers are recommended for such approaches. Furthermore, genotoxicity should be excluded by in vitro testing, so the classification may focus around the three Cramer classes.

Biological materials, such as an ethanol/water extract of the aerial parts of a common herb, must be considered as a complex mixture of phytochemicals, e.g., chlorophyll, tannins, alkaloids, fatty acids, amino acids, sugars and terpenoids. Many of these compounds can be regarded as Cramer Class I, i.e., endogenous or rather inert and consequently of low concern. Alkaloids or specific tannins and terpenoids, for instance, might be of higher concern (cf. Cramer Class II and III). When splitting the systemic exposure dose (SED) quantitatively according to Cramer Class I compounds and Class II and III compounds, the margin of safety (MoS) calculation can be executed separately (cf. Equations (1) and (2) with regard to Cramer Class I and Cramer Class II + III, respectively).

$$
\begin{gathered}
M o S_{\text {fract I }}=\frac{46 \mu \mathrm{g} / \mathrm{kg} \mathrm{bw} / \text { day }}{S E D_{\text {fract } I}} \\
M o S_{\text {fract II+III }}=\frac{2.3 \mu \mathrm{g} / \mathrm{kg} \mathrm{bw} / \text { day }}{S E D_{\text {fract II+III }}}
\end{gathered}
$$

Apart from TTC values, points of departure, such as NOAEL and acceptable daily intake (ADI) can be used if toxicological data are available. Furthermore, rationales, such as history of safe use, can be used for risk assessing. Principally, if the SED is higher than the TTC or an alternative point of departure (with appropriate safety factors), then this must be considered a violation suggesting a lack of safety. The overall scheme of this approach is expressed in Figure 2. 


\section{Biological Mixture}

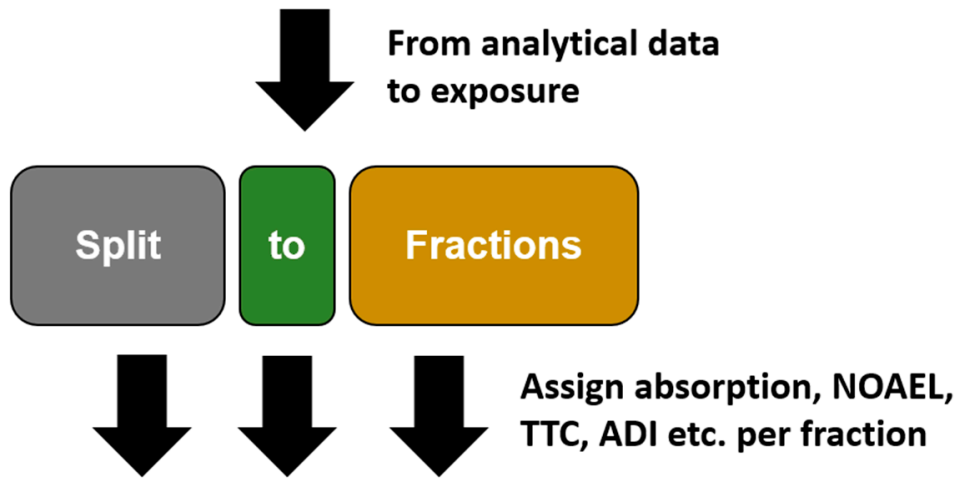

\section{Individual Safety Calculations}

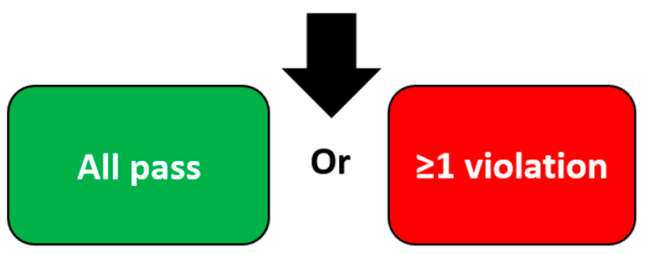

Figure 2. Fractions of concern scheme.

If all fractions are considered safe (i.e., there are no violations present), then the incorporated biological matter is considered safe. However, as chemical information is often not that detailed, there is some flexibility with regard to the definitions of fractions. An example for a fraction could for instance be simple fatty acids and their esters. Beyond this flexibility in the definition of fractions, there is also some flexibility in arguments with regard to safety in both directions, i.e., either arguing for safety and arguing for lack of safety-relevant information. While low dermal absorption, rapid metabolism or information regarding safe use may lead to some tolerance in case of mild MoS violations, aggregated exposure, synergy/additivity towards other ingredients or insufficient analytical data may suggest a MoS even lower than mathematically expressed for the individual raw material. Overall, this approach still entails some degrees of freedom for the assessor.

As mentioned above, interpreting analytical data and defining fractions are probably the most challenging parts. For instance, the composition of Camellia sinensis in the form of green tea, black tea and infusions thereof were described by Chacko and colleagues [20]. However, as the description is rather crudely classified into amino acids, minerals, polyphenols, etc., no chemical data on potentially active polyphenols were provided. Here, the publication of Reto and colleagues [21] might help to identify key components which then can be used for a toxicological literature review or they can be used for an investigation with an appropriate chemoinformatic tool to assign Cramer classes (e.g., ToxTree v3.1.0 [12] or OECD QSAR Toolbox 4.4.1. [13]). While there are many aqueous extracts of green tea being used in cosmetics [22], some may be more concentrated extracts as compared to a simple infusion or even different extraction solvents and process parameters being used. These may influence the final composition of the extract significantly.

Ideally a fractional process would be conducted for a complete cosmetic formulation to address potential additivity/synergy, at least for an obvious MoA, e.g., retinoid-like compounds (cf. vitamin A esters) and compounds with an estrogenic potential, such as parabens, 2-ethylhexanoate and certain steroids [23-26]. 


\section{Perspective}

Assessing the safety of biological matter and the complex mixtures they may entail is not a trivial matter. Voluntary and mandatory bans on animal testing demand novel solutions addressing systemic toxicity [6,27]. Such novel solutions to assess safety may include fractional approaches which can either be used stand-alone or as part of a WoE approach. However, due to the complexity of cosmetic formulations often containing multiple extracts/ferments, it is important to initially obtain a grasp of the relevant chemistry. Particularly for a toxicologically relevant MoA, chemical compounds from mixtures must also be considered towards additivity/synergy and those fractions must be addressed in appropriate safety calculations. Neither the complexity of a mixture nor testing restrictions are reasons for insufficient risk assessments. Despite all restraints, consumer safety is key.

Author Contributions: All authors have read and agreed to the published version of the manuscript.

Funding: This research received no external funding.

Institutional Review Board Statement: Not applicable.

Informed Consent Statement: Not applicable.

Data Availability Statement: Not applicable.

Conflicts of Interest: The authors declare no conflict of interest.

\section{References}

1. Rinaldi, A. Healing beauty? More biotechnology cosmetic products that claim drug-like properties reach the market. EMBO Rep. 2008, 9, 1073-1077. [CrossRef]

2. Allemann, I.B.; Bauman, L. Botanicals in skin care products. Int. J. Dermatol. 2009, 48, 923-934. [CrossRef]

3. Becker, M.; Tickner, J.A. Driving safer products through collaborative innovation: Lessons learned from the Green Chemistry \& Commerce Council's collaborative innovation challenge for safe and effective preservatives for consumer products. Sustain. Chem. Pharm. 2020, 18, 100330.

4. Regulation (EC) No. 1223/2009 of the European Parliament and of the Council of 30 November 2009 on cosmetic products (recast). Off. J. Eur. Union Luxemb. 2009, 342, 59-209.

5. Bernauer, U.; Bodin, L.; Chaudry, Q.; Coenraads, P.J.; Dusinka, M.; Ezendam, J.; Gaffet, E.; Galli, C.L.; Granum, B.; Rogiers, V.; et al. The SCCS Notes of Guidance for the Testing of Cosmetic Ingredients and Their Safety Evaluation, 10th ed.; SCCS: Brussels, Belgium, 2019.

6. Díez-Sales, O.; Nácher, A.; Merino, M.; Merino, V. Chapter 17-Alternative Methods to Animal Testing in Safety Evaluation of Cosmetic Products. Analysis of Cosmetic Products, 2nd ed.; Salvador, A., Chisvert, A., Eds.; Elsevier: Amsterdam, The Netherlands, 2018; pp. 551-584.

7. Constable, A.; Jonas, D.; Cockburn, A.; Davi, A.; Edwards, G.; Hepburn, P.; Herouet-Guicheney, C.; Knowles, M.; Moseley, B.; Oberdörfer, R.; et al. History of safe use as applied to the safety assessment of novel foods and foods derived from genetically modified organisms. Food Chem. Toxicol. 2007, 45, 2513-2525. [CrossRef]

8. ECHA. Read-Across Assessment Framework (RAAF); ECHA: Helsinki, Finland, 2017. [CrossRef]

9. Munro, I.C.; Ford, R.A.; Kennepohl, E.; Sprenger, J.G. Correlation of a structural class with No-Observed-Effect-Levels: A proposal for establishing a threshold of concern. Food Chem. Toxicol. 1996, 34, 829-867. [CrossRef]

10. Yang, C.; Barlow, S.M.; Jacobs, K.L.M.; Vitcheva, V.; Boobis, A.R.; Felter, S.P.; Arvidson, K.B.; Keller, D.; Cronin, M.T.D.; Enoch, S.; et al. Thresholds of Toxicological Concern for cosmetics-related substances: New database, thresholds, and enrichment of chemical space. Food Chem. Toxicol. 2017, 109, 170-193. [CrossRef] [PubMed]

11. Cramer, G.M.; Ford, R.A.; Hall, R.L. Estimation of toxic hazard-a decision tree approach. Food Cosmet. Toxicol. 1978, 16, 255-276. [CrossRef]

12. ToxTree v3.1.0. Toxic Hazard Estimation by Decision Tree Approach. Available online: http://toxtree.sourceforge.net/ (accessed on 11 November 2018).

13. OECD 4.4.1. OECD QSAR Toolbox 4.4.1. Available online: https:/ / qsartoolbox.org/download/ (accessed on 11 January 2021).

14. Kroes, R.; Renwick, A.G.; Cheeseman, M.; Kleiner, J.; Mangelsdorf, I.; Piersma, A.; Schilter, B.; Schlatter, J.; van Schothorst, F.; Vos, J.G.; et al. Structure-based thresholds of toxicological concern (TTC): Guidance for application to substances present at low levels in the diet. Food Chem. Toxicol. 2004, 42, 65-83. [CrossRef]

15. Payne, M.P.; Walsh, P.T. Structure-activity relationships for skin sensitization potential: Development of structural alerts for use in knowledge-based toxicity prediction systems. J. Chem. Inf. Comput. Sci. 1994, 34, 154-161. [CrossRef]

16. Roberts, D.W.; Api, A.M.; Safford, R.J.; Lalko, J.F. Principles for identification of High Potency Category Chemicals for which the Dermal Sensitisation Threshold (DST) approach should not be applied. Regul. Toxicol. Pharmacol. 2015, 72, 683-693. [CrossRef] 
17. Safford, R.J.; Aptula, A.O.; Gilmour, N. Refinement of the Dermal Sensitisation Threshold (DST) approach using a larger dataset and incorporating mechanistic chemistry domains. Regul. Toxicol. Pharmacol. 2011, 60, 218-224. [CrossRef] [PubMed]

18. Safford, R.J.; Api, A.M.; Roberts, D.W.; Lalko, J.F. Extension of the Dermal Sensitisation Threshold (DST) approach to incorporate chemicals classified as reactive. Regul. Toxicol. Pharmacol. 2015, 72, 694-701. [CrossRef] [PubMed]

19. Kawamoto, T.; Fuchs, A.; Fautz, R.; Morita, O. Threshold of Toxicological Concern (TTC) for Botanical Extracts (Botanical-TTC) derived from a meta-analysis of repeated-dose toxicity studies. Toxicol. Lett. 2019, 316, 1-9. [CrossRef] [PubMed]

20. Chacko, S.M.; Thambi, P.T.; Kuttan, R.; Nishigaki, I. Beneficial effects of green tea: A literature review. Chin. Med. 2010, 5, 13. [CrossRef]

21. Reto, M.; Figueira, M.E.; Filipe, H.M.; Almeida, C.M. Chemical composition of green tea (Camellia sinensis) infusions commercialized in Portugal. Plant. Foods Hum. Nutr. 2007, 62, 139-144. [CrossRef]

22. Prasanth, M.I.; Sivamaruthi, B.S.; Chaiyasut, C.; Tencomnao, T. A Review of the Role of Green Tea (Camellia sinensis) in Antiphotoaging, Stress Resistance, Neuroprotection, and Autophagy. Nutrients 2019, 11, 474. [CrossRef]

23. SCHER; SCCS; SCENIHR. Opinion on the Toxicity and Assessment of Chemical Mixtures. 2012. Available online: https: / / ec.europa.eu/health/scientific_committees/environmental_risks/docs/scher_o_155.pdf (accessed on 11 February 2021).

24. Boobis, A.; Budinsky, R.; Collie, S.; Crofton, K.; Embry, M.; Felter, S.; Hertzberg, R.; Kopp, D.; Mihlan, G.; Mumtaz, M.; et al. Critical analysis of literature on low-dose synergy for use in screening chemical mixtures for risk assessment. Crit. Rev. Toxicol. 2011, 41, 369-383. [CrossRef]

25. Kortenkamp, A.; Faust, M.; Scholze, M.; Backhaus, T. Low-level exposure to multiple chemicals: Reason for human health concerns? Environ. Health Perspect. 2007, 115 (Suppl. 1), 106-114. [CrossRef]

26. Martin, O.; Scholze, M.; Ermler, S.; McPhie, J.; Bopp, S.K.; Kienzler, A.; Parissis, N.; Kortenkamp, A. Ten years of research on synergisms and antagonisms in chemical mixtures: A systematic review and quantitative reappraisal of mixture studies. Environ. Int. 2021, 146, 106206. [CrossRef]

27. Antignac, E.; Nohynek, G.J.; Re, T.; Clouzeau, J.; Toutain, H. Safety of botanical ingredients in personal care products/cosmetics. Food and chemical toxicology. Food Chem. Toxicol. 2011, 49, 324-341. [CrossRef] [PubMed] 